\section{Cutaneous lesions as presentation form of mantle cell lymphoma}

\author{
Nayra Merino de Paz, ${ }^{1}$ \\ Marina Rodríguez-Martín, ${ }^{1}$ \\ Patricia Contreras Ferrer, ${ }^{1}$ \\ Sonia García-Hernández, ${ }^{2}$ \\ Nieves Hernández-León, ${ }^{2}$ \\ Antonio Martín-Herrera, ${ }^{2}$ \\ Antonio Noda-Cabrera' \\ 'Dermatology and ${ }^{2}$ Pathology \\ Department, Hospital Universitario \\ de Canarias, University of La Laguna, \\ La Laguna, Tenerife, Spain
}

\begin{abstract}
Mantle cell lymphoma is a type of nonHodgkin lymphoma that affects extranodal areas, especially, bone narrow, digestive tract and Waldeyer ring. Here we report a case of mantle cell lymphoma IV Ann Arbor stage with cutaneous lesions on nasal dorsum and glans penis as the first manifestations. Skin involvement is a very rare manifestation and less than 20 cases have been reported in the literature. The importance of establishing multidisciplinary relationships for a global approach has been shown by this clinical case.
\end{abstract}

\section{Introduction}

Mantle cell lymphoma (MCL) is a type of non-Hodgkin lymphoma that frequently affects extranodal areas, especially, bone narrow, digestive tract and Waldeyer ring. Other areas can also be affected too, however skin involvement is very rare. ${ }^{1,2}$ MCL is characterized by specific morphologic, inmunophenotypic and cytogenetic features [t(11;14)(q13;q32)] and cyclin D1 overexpression. $^{3}$

\section{Case Report}

We report a 73-years-old man with a personal history of bilateral cataracts, facial right paralysis, vertiginous syndrome treated with trimetazidin and teleangiectasic rosacea without treatment. He was referred to our Department from Otolaryngology (ORL) where he was assessed for presenting nasal obstruction three months ago. No fever, asthenia or anorexia were reported. Physical examination revealed: i) papular erythematous, infiltrated, $2.5 \times 2 \mathrm{~cm}$ of diameter lesion on nasal dorsum; ii) exulcerative, exudative lesion with an erythematous edge about $3 \times 4$ $\mathrm{cm}$ of diameter in glans penis were observed (Figure 1). Blood test and cutaneous biopsies were performed.

Histological examination of cutaneous lesions on face and penis showed diffuse lymphocytic proliferation with middle size cells with irregular and clefted nucleous (Figure 2). Moderate mitotic activity was observed. Immunochemistry was positive for CD-20 and D1-Cyclin and negative for CD3 and CD10. Ki67 showed a high proliferation rate (Figure 3 ). These results were consistent with mantle cell lymphoma (MCL). Blood tests, including hemogram, biochemistry and hepatic profile were in normal ranges. ORL study included a turbinate biopsy. Diffuse lymphocytic tumoral proliferation infiltrates with middle size tumoral cells were observed. Tumoral cells showed clefted and irregular nucleous with granular chromatin, moderate mitotic rate and apoptotic bodies. Bone narrow biopsy, thorax Rx, CT scan, MRI, PET and cytogenetic study were performed. Limphocytic infiltrates showing features of MCL were observed in bone narrow. Multiple adenopathies and heterogeneous high intensity sings in both lungs were observed in PET studies (Figure 4). Cytogenetic studies were performed and $\mathrm{t}(11 ; 14)$ was observed by FISH.

After hematologic and dermatologic assessment MCL IVA Ann Arbor stage and intermediate-high IPI diagnosis was established.

Four cycles of R-CHOP were administered every 21 days. A clear improvement after two cycles was observed (Figure 3). Two years later, the patient is still alive with Hematological, ORL and Dermatological periodical controls.

\section{Discussion}

The MCL represents around 10\% of nonHodgkin lymphomas (NHL). It usually affects medium or elder people. Skin involvement is rare, nevertheless, it can be the first manifestation of MCL. Only 19 cases of cutaneous MCL have been reported in the literature. It represents $2-6 \%$ of all NHL and the $17 \%$ are in stage IV. Men are more frequently affected than women (13:4) with a mean age of 63 years-old. Lesions usually appear in trunk, in contrast with our patient that presented the lesions first in face and genital area. A high variety in clinical appearence has been described. Nodular lesions are the most frequent clinical presentation, but macules, papules or plaques have been described too.
Correspondence: Nayra Merino de Paz, Servicio de Dermatología, Hospital Universitario de Canarias, Ofra s/n. La Laguna, Santa Cruz de Tenerife, 38320 Canary Islands, Spain.

Tel. +34.22.678.492 - Fax: +34.22.319.293.

E-mail: nayradepazhotmail.com

Key words: cutaneous lymphoma, non-Hodgkin, mantle cell.

Contributions: NMdP, NRM, AND, manuscript writing; SGH, NHL, AMH, pathology studing; NMdP, PCF, SGH, NHL, AMH, data collecting and analyzing; MRM, PCF, ANC, manuscript reviewing.

Conflict of interest disclosure: any author have a perceived or actual conflict of interest.

Received for publication: 21 July 2011.

Revision received: 7 October 2011.

Accepted for publication: 9 November 2011.

This work is licensed under a Creative Commons Attribution NonCommercial 3.0 License (CC BYNC 3.0).

CC Copyright N. Merino de Paz et al., 2011 Licensee PAGEPress, Italy

Dermatology Reports 2011; 3:e51

doi:10.4081/dr.2011.e51

Our patient presented two diferent clinical forms; nasal dorsum with papular presentation and ulcerative clinical appearence in glans penis. Genital ulcerative form of cutaneous MCL is uncommon. Up to $82 \%$ of patients with skin lesions present coexisting extracutaneous involvement, so extension studies are necessary to find other affected organs including blood tests, Rx, CT scan, MRI and PET. MCL has a median survival of 35 years, with a better prognosis in patients with non-nodal disease. MCL is associated to a poor prognosis. ${ }^{3,4}$ The median survival time

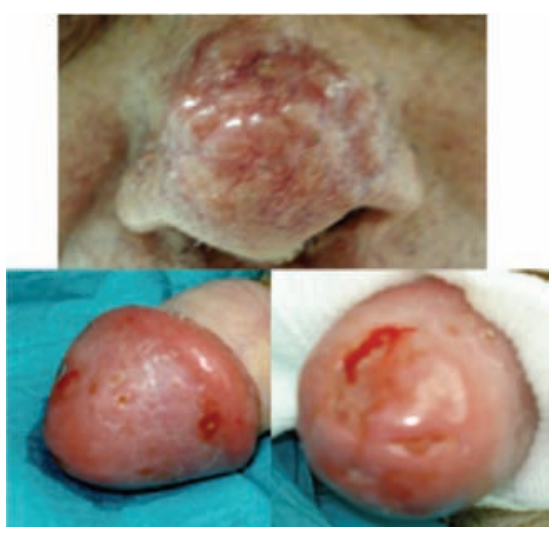

Figure 1. Clinical appearance of cutaneous lesions on face and glans penis. 


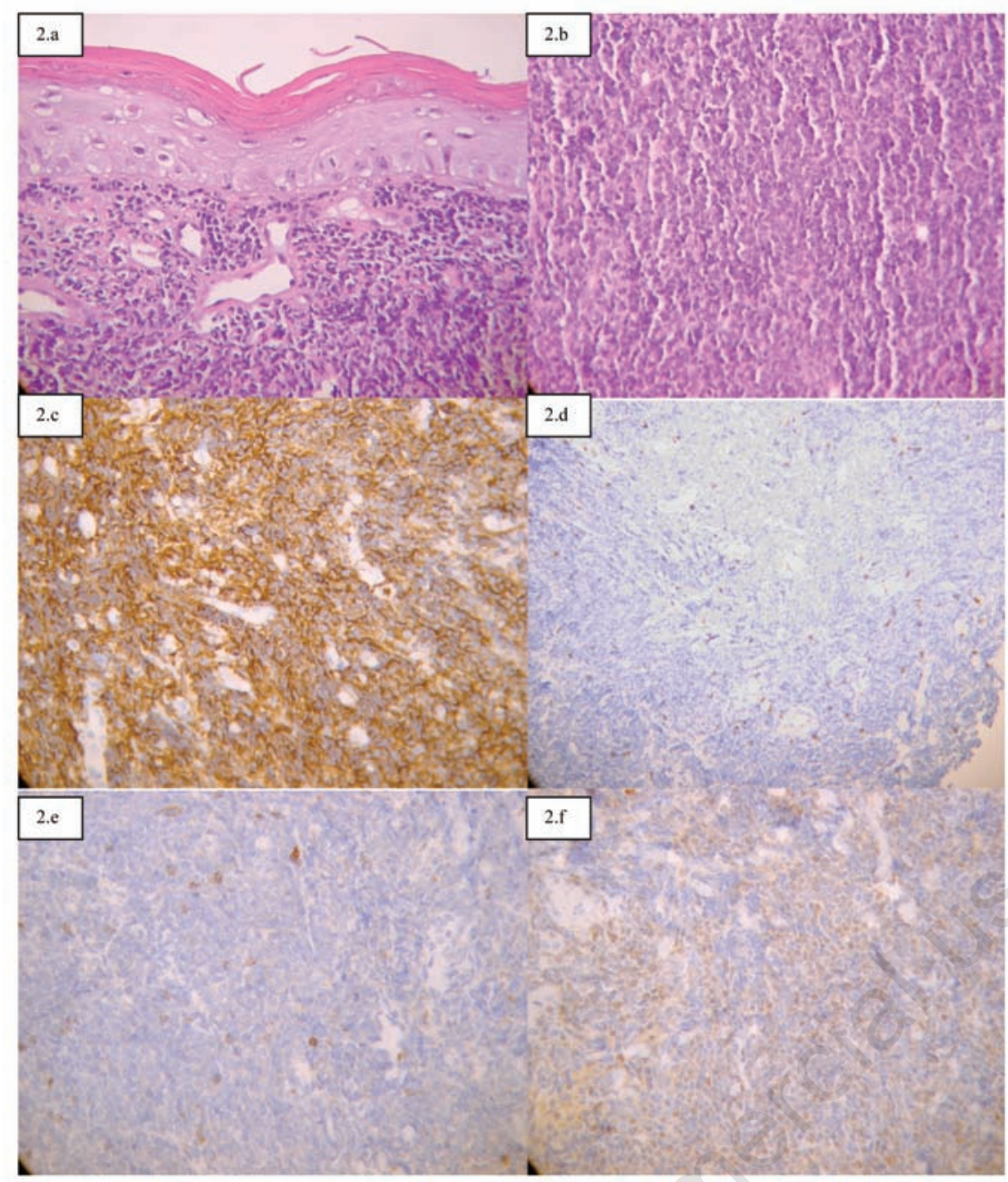

Figure 2. Histological finding: a, b) Hema-toxylin and Eosin; c) CD20; d) CD3; e) CD10 and f) D1-Cyclin stains.

Table 1. Skin manifestation of mantle cell lymphoma.

\begin{tabular}{rlllll} 
N & Author & Age/Gender & $\begin{array}{c}\text { Extracutaneous } \\
\text { involvement }\end{array}$ & Stage & Prognosis \\
1 & Ellison & $66 \mathrm{M}$ & Yes & IV & D (55 days after hospitalizazion) \\
2 & Geerts & $65 \mathrm{~F}$ & Yes & IVA & D (1.5 years after diagnosis) \\
\hline 3 & Geerts & $77 \mathrm{~F}$ & Yes & IVA & \\
4 & Bertero & $51 \mathrm{M}$ & Yes & IVA & A (17 years after diagnosis) \\
\hline 5 & Bertero & $78 \mathrm{~F}$ & No & IE & D (3 years after diagnosis) \\
6 & Bertero & $43 \mathrm{M}$ & Yes & IVA & A \\
\hline 7 & Bertero & $22 \mathrm{M}$ & No & IE & A \\
8 & Marti & $61 \mathrm{~F}$ & Yes & IVA & D (15 months after diagnosis) \\
\hline 9 & Moody & $47 \mathrm{M}$ & Yes & IVA & A (3 years after onset) \\
10 & Dubus & $56 \mathrm{M}$ & Yes & IVA & D (1 year after treatment) \\
\hline 11 & Dubus & $89 \mathrm{M}$ & Yes & IVA & D (5 days after diagnosis) \\
12 & Dubus & $72 \mathrm{M}$ & Yes & IVA & A (1 year after treatment) \\
\hline 13 & Sen & $85 \mathrm{M}$ & Yes & IVB & D (20 months after onset) \\
14 & Sen & $76 \mathrm{M}$ & No & IE & A (30 months after onset) \\
\hline 15 & Sen & $56 \mathrm{M}$ & Yes & IVA & A (21 months after onset) \\
16 & Sen & $57 \mathrm{M}$ & Yes & IVB & D (19 months after onset) \\
\hline 17 & Sen & $61 \mathrm{M}$ & Yes & IVB & D (17 months after onset) \\
18 & Motegi & $62 \mathrm{M}$ & Yes & & A (4 months after diagnosis) \\
\hline 19 & Estrozi & $72 \mathrm{M}$ & Yes & IVA & A (6 months after diagnosis) \\
20 & Merino & $73 \mathrm{M}$ & Yes & IVA & A (2 years after diagnosis) \\
\hline Most of data adapted from Motegi S. Okada E Nagai Y Tamura A Ishikawa 0. Skin manifestation of mantle cell lymphoma Eur J Dermatol.
\end{tabular}

Most of data adapted from Motegi S, Okada E, Nagai Y, Tamura A, Ishikawa O. Skin manifestation of mantle cell lymphoma. Eur J Dermatol. 2006 Jul-Aug; 16(4):435-8. D, dead; A, alive.

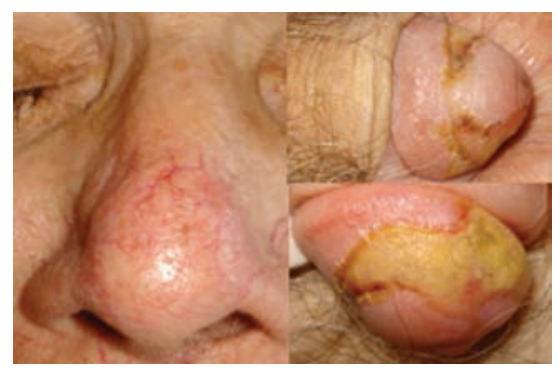

Figure 3. Clinical appearance after treatment.

is aproximately 3 years (range $2-5$ years). The ten year survival rate is only $5-10 \%$. Younger age and limited diseases are favorable prognostic features. Survival behavior of patients with cutaneous involvement is showed in Table 1. The skin involvement is considerer as independent prognostic factor, but it is uncertain. ${ }^{3,5,6}$ Treatment is difficult. First-line treatments for solitary lesions include surgical excision, antibiotics, and radiotherapy. Systemic involvement needs an aggressive management. Only $30 \%$ of patients experienced a complete response. It is based in single akylating agents, CVP (cyclophosphamide, vincristine and prednisone) and $\mathrm{CHOP}$ (cyclophosphamide, doxorubicin, vincristine and prednisone) regimens, Hyper-CVAD (hyperfractionated cyclophosphamide, doxorubicin, vincristine, and dexamethasone) with or without rituximab, R-CHOP (CHOP plus rituximab) or Hyper-CVAD with autologous stem cell transplantation. Our patient was treated with R-CHOP with a complete response. R-CHOP have showed a higher complete response rate than $\mathrm{CHOP}$. Complications from chemotherapy may include infection, neutropenia, anemia, and thrombocytopenia, fatigue, neuropathy, dehydration after diarrhea or vomiting and cardiac toxicity from doxorubicin. ${ }^{6,7}$ Only ORL area involvement is also rare. So, our patient presented with a very unique clinical picture. In fact, sinonasal lymphomas are relatively uncommon and represent less than $1 \%$ of all head and neck malignancies. T/NK cell lymphoma is the most frequent in nasal cavity, however B-cell lymphoma is the main type in paranasal sinuses. ${ }^{8,9}$ So, here we present a rare case of MCL with cutaneous and nasal cavity lesions as presentation signs. The role of dermatologists is very important, in establishing an early diagnosis. We have to consider this entity in the dermatologic differential diagnosis of tumours and we have to be aware about the importance of multidisciplinary approach. 


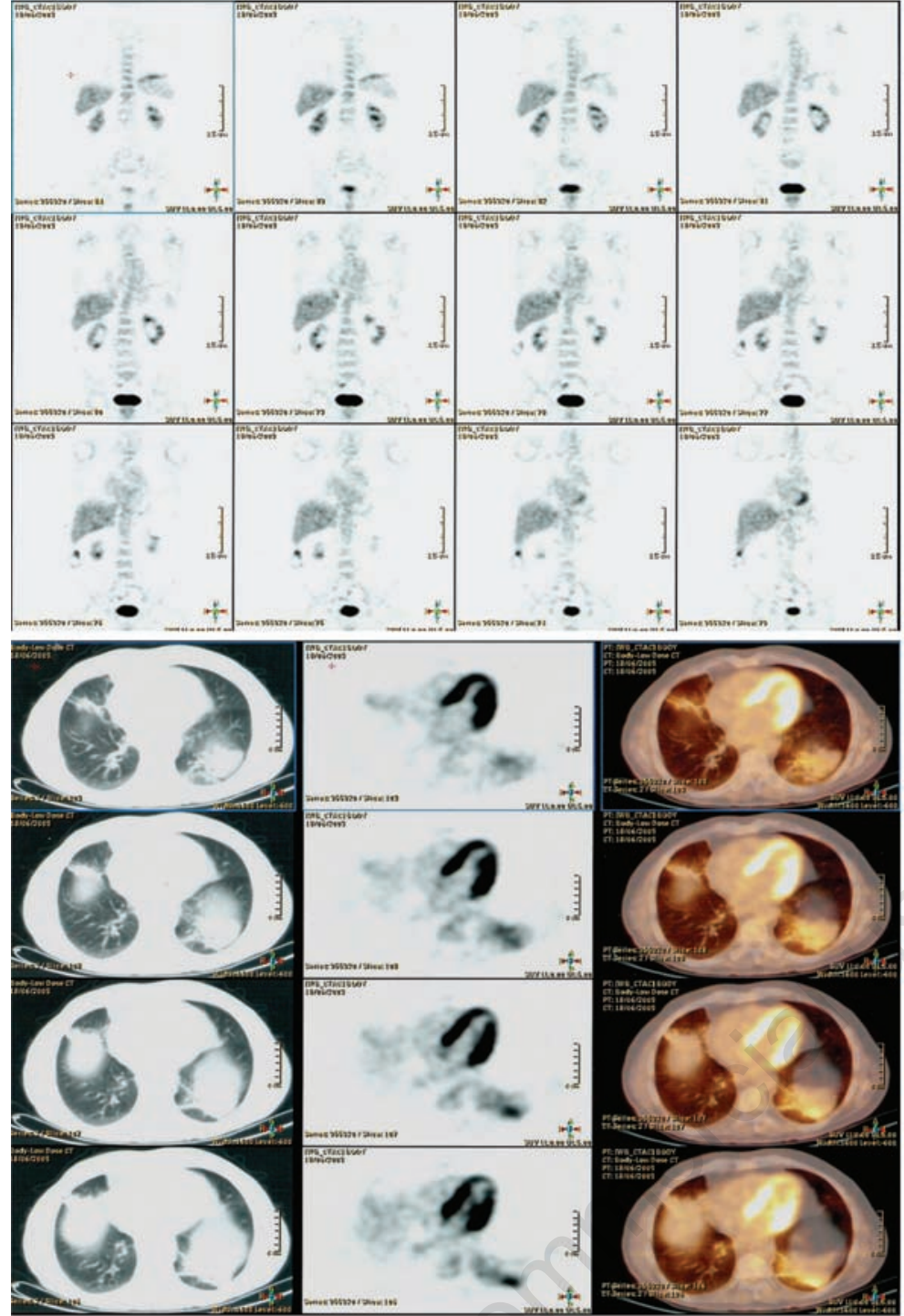

Figure 4. Upper side: Preauricular, retroauricular, occipital, submandibular, subcarinal, right hilum and groin lymphadenopathies, heterogeneuos. Lower side: High intesity sings in both lungs were observed in PET studies.

\section{References}

1. Estrozi B, Sanches JA Jr, Varela PC, Bacchi CE. Primary cutaneous blastoid mantle cell lymphoma-case report. Am J Dermatopathol 2009;31:398-400.

2. Sen F, Medeiros LJ, Lu D, et al. Mantle cell lymphoma involving skin: cutaneous lesions may be the first manifestation of disease and tumors often have blastoid cytologic features. Am J Surg Pathol 2002 26:1312-8.

3. Motegi S, Okada E, Nagai Y, e al. Skin manifestation of mantle cell lymphoma. Eur J Dermatol 2006;16:435-8.

4. Lai R, Medeiros LJ. Pathologic diagnosis of mantle cell lymphoma. Clin Lymphoma 2000;1:197-208

5. Bosch F, Lopez-Guillermo A, Campo E, et al. Mantle cell lymphoma: presenting features, response to therapy, and prognostic factors. Cancer 1998;1:567-75.

6. Swerdlow SH, Kurrer M, Bernengo M, Buchner S. Cutaneous involvement in primary extracutaneous B-cell lymphoma. In: Weedon D, LeBoit P, Burg G, Sarasin A, eds. Pathology and Genetics of Tumors of the Skin: WHO Classification of Tumors. Lyon: IARC, 2005. pp 204-6.

7. Weigert 0 , Unterhalt M, Hiddemann W, Dreyling M. Mantle cell lymphoma: stateof-the-art management and future perspective. Leuk Lymphoma 2009;50:193750.

8. Van Prooyen Keyzer S, Eloy P, Delos M, et al. Sinonasal lymphomas. Case report. Acta Otorhinolaryngol Belg 2000;54:45-51.

9. Vidal RW, Devaney K, Ferlito A, et al. Sinonasal malignant lymphomas: a distinct clinicopathological category.Ann Otol Rhinol Laryngol 1999;108:411-9. 